Article

\title{
Quantification of Seasonal Precipitation over the upper Chao Phraya River Basin in the Past Fifty Years Based on Monsoon and El Niño/Southern Oscillation Related Climate Indices
}

\author{
Tsuyoshi Kinouchi ${ }^{1, *}$, Gakuji Yamamoto ${ }^{1}$, Atchara Komsai ${ }^{1}$ and Winai Liengcharernsit ${ }^{2}$ \\ 1 Department of Transdisciplinary Science and Engineering, School of Environment and Society, \\ Tokyo Institute of Technology, Yokohama 226-8503, Japan; yamamoto.g.ab@m.titech.ac.jp (G.Y.); \\ komsai.a.aa@m.titech.ac.jp (A.K.) \\ 2 Department of Environmental Engineering, Faculty of Engineering, Kasetsart University, Bangkok 10900, \\ Thailand; fengwnl@ku.ac.th \\ * $\quad$ Correspondence: kinouchi.t.ab@m.titech.ac.jp; Tel.: +81-45-924-5524
}

Received: 29 April 2018; Accepted: 13 June 2018; Published: 17 June 2018

\begin{abstract}
For better water resources management, we proposed a method to estimate basin-scale seasonal rainfall over selected areas of the Chao Phraya River Basin, Thailand, from existing climate indices that represent variations in the Asian summer monsoon, the El Niño/Southern Oscillation, and sea surface temperatures (SST) in the Pacific Ocean. The basin-scale seasonal rainfall between 1965 and 2015 was calculated for the upper Ping River Basin (PRB) and the upper Nan River Basin (NRB) from a gridded rainfall dataset and rainfall data collected at several gauging stations. The corresponding climate indices, i.e., the Equatorial-Southern Oscillation Index (EQ-SOI), Indian Monsoon Index (IMI), and SST-related indices, were examined to quantify seasonal rainfall. Based on variations in the rainfall anomaly and each climate index, we found that IMI is the primary variable that can explain variations in seasonal rainfall when EQ-SOI is negative. Through a multiple regression analysis, we found that EQ-SOI and two SST-related indices, i.e., Pacific Decadal Oscillation Index (PDO) and SST anomalies in the tropical western Pacific $\left(\mathrm{SST}_{\mathrm{NW}}\right)$, can quantify the seasonal rainfall for years with positive EQ-SOI. The seasonal rainfall calculated for 1975 to 2015 based on the proposed method was highly correlated with the observed rainfall, with correlation coefficients of 0.8 and 0.86 for PRB and NRB, respectively. These results suggest that the existing indices are useful for quantifying basin-scale seasonal rainfall, provided a proper classification and combination of the climate indices are introduced. The developed method could forecast seasonal rainfall over the target basins if well-forecasted climate indices are provided with sufficient leading time.
\end{abstract}

Keywords: seasonal rainfall; upper Chao Phraya River Basin; El Niño/Southern Oscillation; Indian Monsoon; sea surface temperatures

\section{Introduction}

Recently, many regions have endured significant impacts from extreme floods and droughts, including Southeastern Asian countries [1-4]; disastrous floods and droughts are expected to occur more frequently due to the changing climate [2,5-7]. To mitigate the impacts of extreme hydro-meteorological events, well-prepared water resource management practices are required, for which the quantification of rainfall and resulting runoff is key information.

In Thailand, a devastating flood occurred in the Chao Phraya River Basin in 2011 [8,9], resulting in a change in policy to focus more on flood mitigation. However, the basin suffered a serious drought 
during 2015 and 2016 due to the reduced water storage of the major reservoirs, i.e., the Bhumibol and Sirikit Dam reservoirs during the preceding years and the limited amount of rainfall in the wet season of 2015. To sustain socio-economic activities in the downstream areas of the Chao Phraya River Basin, sufficient water storage in these reservoirs is required before the dry season while enough empty volume should be maintained for flood-control during the rainy season. Therefore, water release from the reservoirs needs to be well-managed by forecasting the areal rainfall and its resulting inflows to the reservoirs with sufficient leading time.

Different approaches have been adopted to quantify or forecast rainfall in Thailand using climate indices. Most approaches are based on a simple linear correlation method [10,11], and a limited number of works have considered multiple indices using a linear multiple-regression model and a non-parametric method [12]. The linear regression approach is conventional, but not suitable if the rainfall is non-linearly related to climate indices. The non-parametric method is advantageous in this situation, although its implementation is complicated.

Furthermore, previous studies focused on rainfall at a limited number of sites with shorter duration (for example, [12]); however, for water resources management purposes, rainfall must be estimated to represent the entire rainy season at regional or basin-scales, rather than the smaller area represented by individual gauging stations.

In this study, we attempt to develop a method that can relate seasonal rainfall over the two major upstream sub-basins of the Chao Phraya River Basin draining to the Bhumibol and Sirikit Dam reservoirs, i.e., the upper Ping River Basin (PRB) and the upper Nan River Basin (NRB), to multiple climate indices that are predictable prior to the rainy season. The Bhumibol and Sirikit Dam reservoirs are the first and second-largest reservoirs in Thailand and provide water for various economic and environmental purposes [13]. The areal-averaged rainfall data of the rainy seasons between 1965 and 2015 were used to determine a relationship between the total rainfall and selected indices, i.e., the Southern Oscillation index (Equatorial SOI, hereafter EQ-SOI), Indian Monsoon index (IMI), El Niño/Southern Oscillation index (SSTs), and the Pacific Decadal Oscillation index (PDO).

\section{Study Area and Data Analysis}

\subsection{Study Area}

Two major sub-basins of the Chao Phraya River Basin (CPRB) draining to the Bhumibol and Sirikit Dam reservoirs, i.e., the PRB and NRB, were selected as study sites, respectively (Figure 1). The PRB and NRB cover $26,300 \mathrm{~km}^{2}$ and $11,950 \mathrm{~km}^{2}$, respectively. The Bhumibol and Sirikit Dam reservoirs discharge a significant amount of water for domestic and industrial use, as well as for irrigation and environmental purposes [13,14]. Although domestic usage receives priority in the water allocation of the Chao Phraya River Basin, a large area of farmland requires a large amount of water for irrigation, especially during the dry season, and depends on the two major dams and other mediumto small-scale reservoirs. Therefore, it is highly important to know the volume of water available in these reservoirs before the dry season arrives.

The climate of the study area is characterized by distinct rainy and dry seasons (Figure 2). During the rainy season, the amount of precipitation and its areal extent in the CPRB are caused by the southwest monsoons, together with typhoons, monsoon troughs, and depressions from the South China Sea. The mean monthly rainfall over the study area is large during May and October (PRB) or September (NRB), which corresponds to the southwest monsoon periods [15] (Figure 2). 


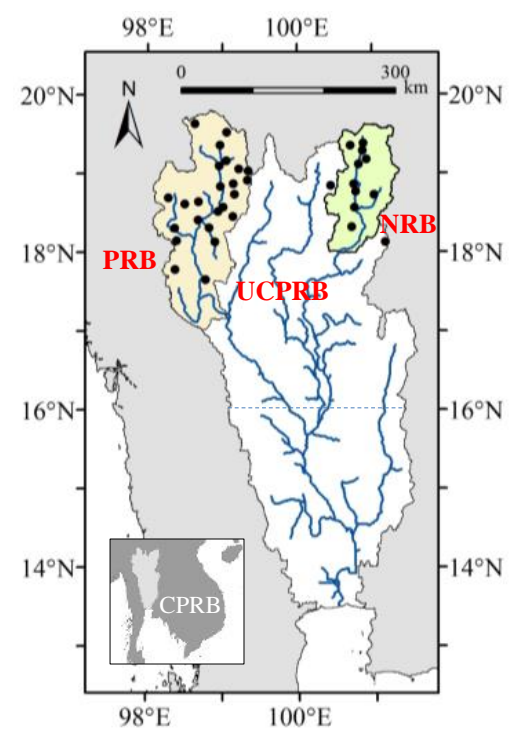

Figure 1. Location of the upper Ping River Basin (PRB) and the upper Nan River Basin (NRB). The inset shows the area of the Chao Phraya River Basin (CPRB). The Upper Chao Phraya River Basin (UCPRB) is defined to cover the area north of $16^{\circ} \mathrm{N}$. The black dots indicate the locations of rain gauges used to estimate areal rainfall since 2001.

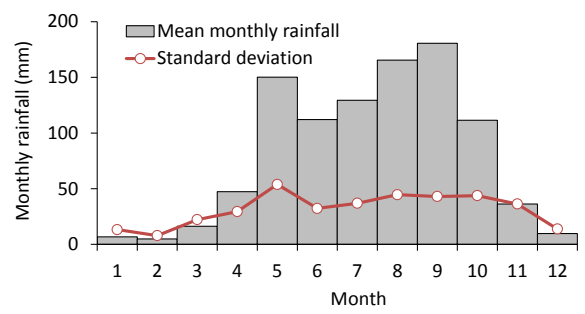

(a)

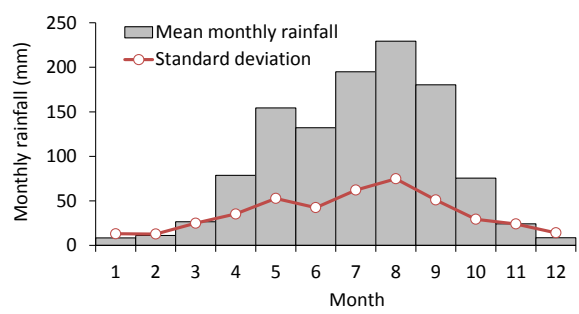

(b)

Figure 2. Mean monthly areal-averaged rainfall for the period from 1975 to 2015 over (a) PRB and (b) NRB.

\subsection{Data Source}

To determine the relationship between seasonal rainfall and regional climate conditions, we used the areal rainfall obtained from gridded and gauged rainfalls, and indices representing the regional climate conditions, such as the monsoon and El Niño/Southern Oscillation (ENSO). The area-averaged rainfall during the rainy season was calculated for the period between April and October utilizing a gridded rainfall dataset (APHRODITE, [16]) and rain-gauge data collected by the Royal Irrigation Department of Thailand (RID) at multiple sites located in the PRB and NRB (Figure 1). Rainfall in April is included in the rainy season as the onset of the summer rainy season begins earlier in the inland Indochina in late April to May [17], and the monthly rainfall in April is comparable to that of October for NRB (Figure 2). As the APHRODITE dataset only contains data until 2007, the areal rainfall during 2008-2015 was estimated from the original relationship between the areal-mean monthly rainfalls obtained from the APHRODITE dataset and those calculated by the Thiessen Polygon applied to the rain-gauge data of RID for the period from 1980 to 2000 (see the supplement for detailed method information to calculate the areal rainfall).

The climate indices used in the analysis include the EQ-SOI, IMI, SST anomaly over selected domains in the Pacific Ocean, PDO, and the Indian Ocean Dipole Mode index (DMI). The definition of each index is listed in Table 1. EQ-SOI is superior to SOI in representing the strength of trade winds over the tropical Pacific as one of the domains for calculating EQ-SOI (SLP.2 in Figure 3) is closer to 
our study area while SOI is defined as the difference between the sea level pressure at two specific locations in the Southern Hemisphere (Tahiti and Darwin). IMI is the difference between the 850-hPa zonal wind in domain U850.1 and that in domain U850.2 (Figure 3) [18]. A larger IMI indicates a stronger summer monsoon over the Bay of Bengal. Anomalies in sea surface temperature (SST) are defined for the selected domains over the tropical Pacific (Table 1). If EQ-SOI is positive, which likely corresponds to stronger trade winds than normal, the sea surface temperature in these domains may affect the supply of atmospheric vapor in the leeward region. PDO is an anomaly pattern of SST in the Pacific Ocean (north of $20^{\circ} \mathrm{N}$ ) that shifts phases on an inter-decadal time scale that usually covers over 10 years [19]. A positive (negative) value of PDO indicates that SST is lower (higher) than normal in the northwestern Pacific. The intensity of the Indian Ocean dipole mode (IOD) is represented by the Dipole Mode Index (DMI) as an anomalous SST gradient between two selected domains (Table 1) [20]. The domain for calculating the finally selected indices is illustrated in Figure 3.

Table 1. Description of climate indices used in this study.

\begin{tabular}{|c|c|c|}
\hline Index & Definition & Data Sources \\
\hline EQ-SOI & $\begin{array}{l}\text { The difference between the area-averaged sea level pressure in an area of the } \\
\text { eastern equatorial Pacific }\left(80^{\circ} \mathrm{W}-130^{\circ} \mathrm{W}, 5^{\circ} \mathrm{N}-5^{\circ} \mathrm{S} \text {; indicated as SLP.1 in }\right. \\
\text { Figure 3) and an area over Indonesia }\left(90^{\circ} \mathrm{E}-140^{\circ} \mathrm{E}, 5^{\circ} \mathrm{N}-5^{\circ} \mathrm{S} \text {; SLP.2 in Figure 3) }\right.\end{array}$ & [21] \\
\hline IMI & $\begin{array}{l}\text { The difference between the 850-hPa zonal wind in the domain of } 40^{\circ} \mathrm{E}-80^{\circ} \mathrm{E}, 5^{\circ} \\
\mathrm{N}-15^{\circ} \mathrm{N} \text { (indicated as U850.1 in Figure } 3 \text { ) and that in the domain of } 70^{\circ} \mathrm{E}-90^{\circ} \mathrm{E} \text {, } \\
\left.20^{\circ} \mathrm{N}-30^{\circ} \mathrm{N} \text { (U850.2 in Figure } 3\right)\end{array}$ & [22] \\
\hline $\begin{array}{l}\text { SST } \\
\text { NINO.WEST } \\
\text { NINO.3 } \\
\text { NINO.4 } \\
\text { NINO.34 }\end{array}$ & $\begin{array}{l}\text { Anomalies in sea surface temperature for the domain over } \\
\text { the western tropical Pacific }\left(130^{\circ} \mathrm{E}-150^{\circ} \mathrm{E}, 15^{\circ} \mathrm{N}-\mathrm{EQ}\right) \\
\text { the eastern equatorial Pacific }\left(150^{\circ} \mathrm{W}-90^{\circ} \mathrm{W}, 5^{\circ} \mathrm{N}-5^{\circ} \mathrm{S}\right) \\
\text { the central equatorial Pacific }\left(160^{\circ} \mathrm{E}-150^{\circ} \mathrm{W}, 5^{\circ} \mathrm{N}-5^{\circ} \mathrm{S}\right) \\
\text { the central/eastern equatorial Pacific }\left(170^{\circ} \mathrm{W}-120^{\circ} \mathrm{W}, 5^{\circ} \mathrm{N}-5^{\circ} \mathrm{S}\right)\end{array}$ & [23] \\
\hline PDO & $\begin{array}{l}\text { The leading principal component of the mean monthly SST in the Pacific Ocean } \\
\text { north of } 20^{\circ} \mathrm{N} \text { [19] }\end{array}$ & [24] \\
\hline DMI & $\begin{array}{l}\text { An anomalous SST gradient between the western }\left(50^{\circ} \mathrm{E}-70^{\circ} \mathrm{E}, 10^{\circ} \mathrm{S}-10^{\circ} \mathrm{N}\right) \text { and } \\
\text { southeastern equatorial Indian Ocean }\left(90^{\circ} \mathrm{E}-110^{\circ} \mathrm{E}, 10^{\circ} \mathrm{S}-0^{\circ} \mathrm{N}\right)\end{array}$ & [25] \\
\hline
\end{tabular}

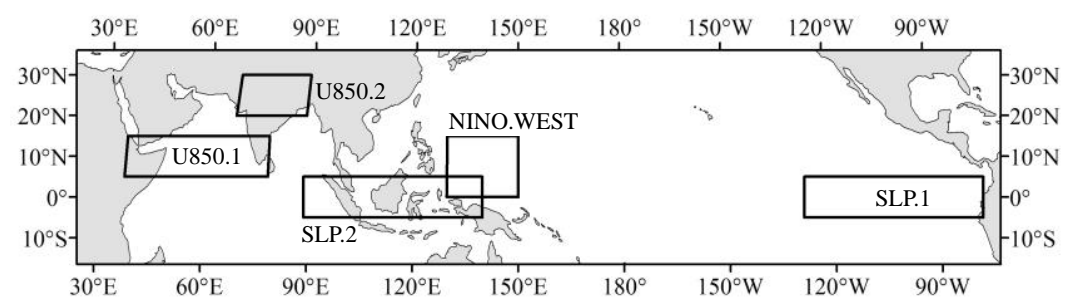

Figure 3. Domains related with each climate index finally employed in the proposed method (the domain related with PDO is not shown).

The EQ-SOI and IMI data were obtained from the NOAA National Weather Service [21] and the International Pacific Research Center (IPRC), University of Hawaii [22], respectively. The SST indices over NINO.WEST, NINO.3, NINO.4, and NINO.34 were obtained from the Japan Meteorological Agency [23]. The PDO and DMI data were obtained from the NOAA Earth System Research Laboratory (ESRL) [24] and the Japan Agency for Marine-Earth Science and Technology (JAMSTEC) [25], respectively.

\subsection{Overview of Data Analysis}

To quantify the seasonal rainfall from existing climate indices, we assume that a functional relationship between the total rainfall from April to October and the selected climate indices averaged over the same period can be applied, which may take the form of Equation (1): 


$$
\mathrm{TR}=f(\mathrm{EQ}-\mathrm{SOI}, \mathrm{IMI}, \mathrm{PDO}, \mathrm{DMI}, \mathrm{SST})
$$

where TR $(\mathrm{mm})$ is the areal-averaged seasonal rainfall during April and October, and SST represents the SST anomaly over a certain domain in the Pacific Ocean.

Based on our preliminary check for coherent variations in TR and each index, we found that the influential climate factors differed depending on EQ-SOI; thus, we classified the data into two categories with respect to EQ-SOI. When EQ-SOI is negative, we simplified Equation (1) to utilize a single independent variable (IMI), however, when EQ-SOI is positive, multiple regression analysis was used to determine the exact form of Equation (1). We obtained the functional relationship by parameter optimization (when EQ-SOI is negative) and the multiple regression analysis (when EQ-SOI is positive) based on the data for 1975 to 2015, and verified it for data between 1965 and 1974.

\section{Results}

\subsection{Characteristics of Rainfall and Corresponding Climate Indices}

Areal rainfall data indicates that over $90 \%$ of the annual rainfall occurs during April and October almost every year, with the largest mean monthly rainfall occurring in September (PRB) or August (NRB) (Figure 2). In the NRB, the mean monthly rainfall in April is larger than that in October. The anomaly of seasonal rainfall from April to October ranges from -291 to $367 \mathrm{~mm}$ for PRB and from -315 to $444 \mathrm{~mm}$ for NRB, with mean rainfall of $890 \mathrm{~mm}$ and $1073 \mathrm{~mm}$, and standard deviations of $124 \mathrm{~mm}$ and $165 \mathrm{~mm}$ for PRB and NRB, respectively (Figure 4).

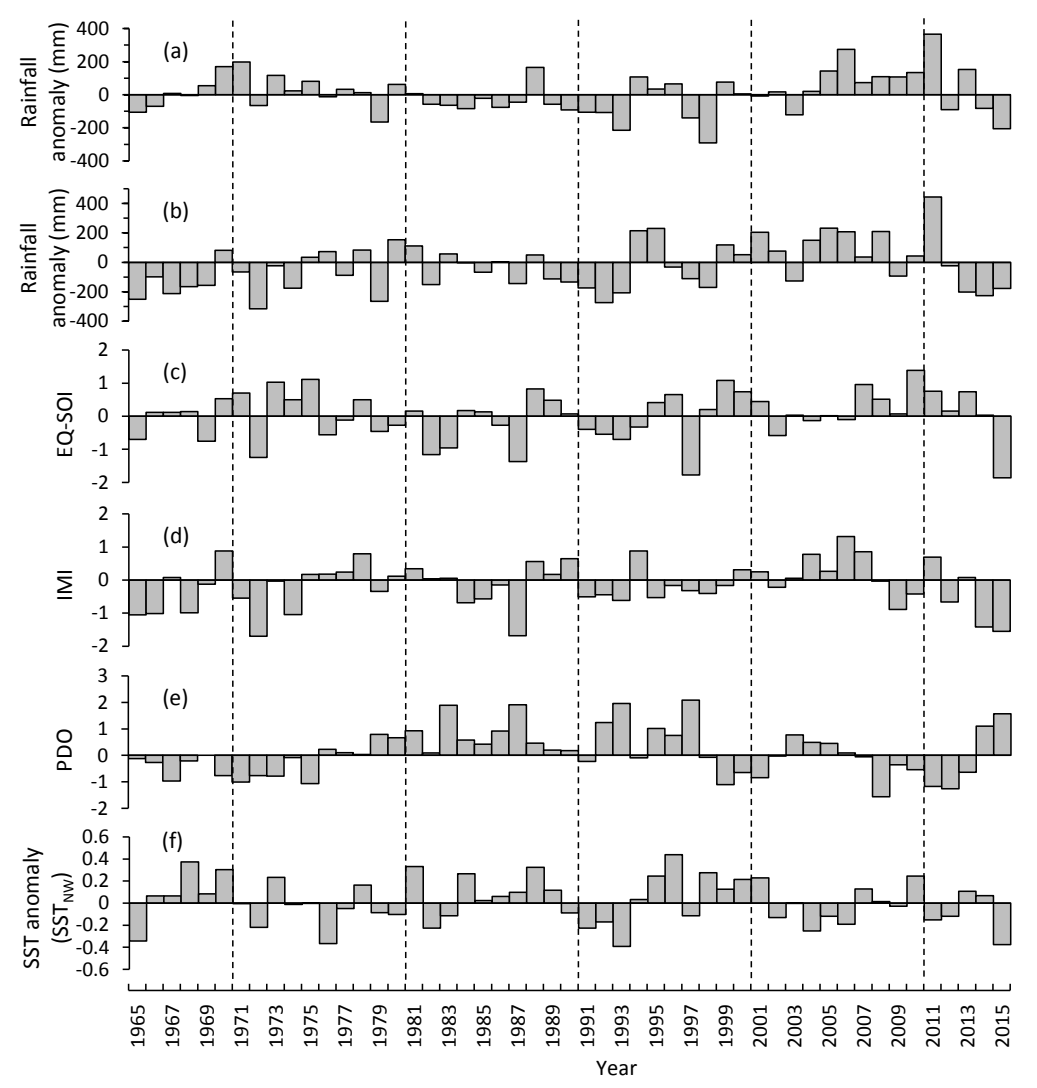

Figure 4. Anomalies of the seasonal rainfall and finally selected climate indices for the period between 1965 and 2015. (a) Rainfall anomaly in PRB; (b) Rainfall anomaly in NRB; (c) EQ-SOI; (d) IMI; (e) PDO; and (f) SST $_{\text {NW }}$ (SST anomaly over NINO.WEST). Each decade is separated by dashed lines. The rainfall anomaly is calculated as the deviation from the mean rainfall for the period from 1975 to 2015. 
The areal rainfall over PRB tends to be smaller and less variable than that over NRB, which could be due to the effect of the Dawna Range located on the western side of PRB and the limited influence of the easterly wind. The rainfall anomalies for PRB and NRB tended to be positively large between 2004 and 2011 (excluding some years), while negative anomalies were predominant during 1981-1993 and since 2012 (Figure 4). The average of each climate index between April and October is plotted in Figure 4. In years with negative EQ-SOI and IMI (1979, 1991, 1992, 1993, 1997, and 2015), it is likely that the rainfall anomalies are also negative. A positive rainfall anomaly was found in years with positively large IMI (1994 and 2006) and negative EQ-SOI. PDO was large and negative between 2008 and 2013, when the rainfall anomaly is mostly positive. EQ-SOI was negatively correlated with PDO on inter-annual and decadal time scales. Coherent variation is observed between EQ-SOI and the SST anomaly over NINO.WEST (SST $\mathrm{NW}_{\text {) }}$ in both the negative and positive phases. However, the influence of $\mathrm{SST}_{\mathrm{NW}}$ on rainfall anomalies is not clear from Figure 4.

\subsection{Relationship between Seasonal Rainfall and Climate Indices}

Based on the coherent variation of the rainfall anomaly and each climate index described in the previous section, we classified the rainfall dataset and climate indices into two groups depending on EQ-SOI (the threshold value was slightly larger than 0). Seasonal rainfall is primarily related to IMI when EQ-SOI is negative and approaches the lower (upper) bound when IMI is negatively (positively) large (Figure 5). This suggests that, when EQ-SOI is negative, the effect of the monsoon on rainfall over the Indochina Peninsula is predominant due to the lower influence of the weaker surface trade winds. A nonlinear equation based on a sigmoid function (Equation (2)) was applied to the relationship between IMI and seasonal rainfall TR $(\mathrm{mm})$ by calibrating the parameters in Equation (2) to minimize the root mean square error (RMSE) between the actual and calculated rainfalls (Figure 5):

$$
\mathrm{TR}=\frac{a}{1+\exp (-\lambda \times \mathrm{IMI})}+b
$$

where $a, b$, and $\lambda$ are the parameters calibrated for each basin (Table 2).
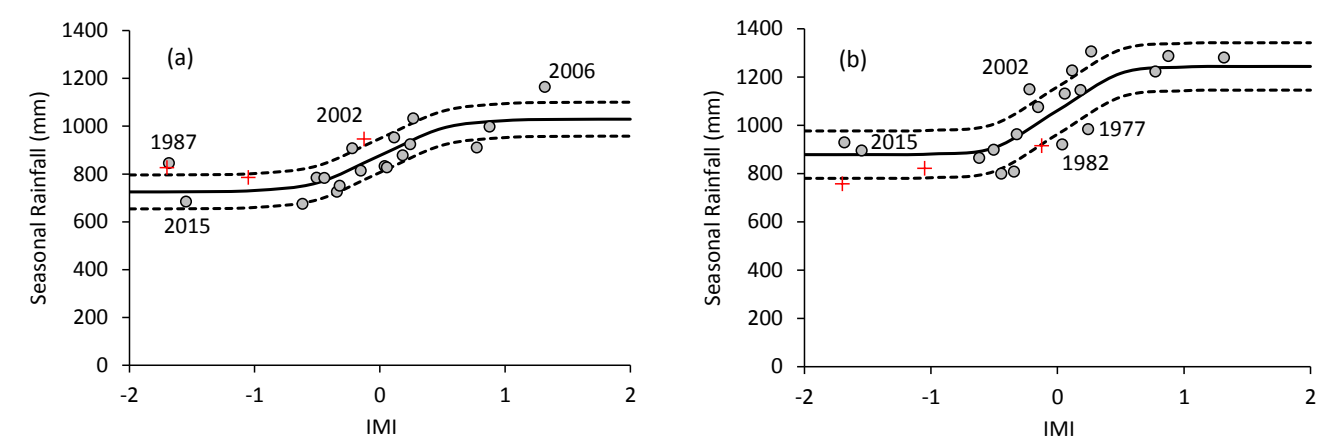

Figure 5. The relation between the seasonal rainfall and IMI for (a) PRB and (b) NRB. Two dashed lines are separated from the solid line (Equation (1)) by the standard deviation of the error between the observed and estimated seasonal rainfalls. The gray circles are the data used for calibrating the parameters, and the cross marks indicate data for 1965, 1969, and 1972, which were not used for calibration.

Table 2. Calibrated parameters used in Equation (1).

\begin{tabular}{cccc}
\hline Basin & $\boldsymbol{a}(\mathbf{m m})$ & $\boldsymbol{b}(\mathbf{m m})$ & $\boldsymbol{\lambda}$ \\
\hline PRB & 302.4 & 723.0 & 4.107 \\
NRB & 395.1 & 870.6 & 4.734 \\
\hline
\end{tabular}


The most recent drought year, 2015, is plotted close to the curve of Equation (2) (Figure 5). The difference between the estimated (solid line) and observed rainfall in some years is large (Figure 6). Although we checked the influence of other factors (EQ-SOI, PDO, and other SST-related indices), none of them were likely to be responsible for this difference. Data for years before 1975 are also plotted in Figure 5, indicating that the seasonal rainfall for these years can also be represented by Equation (2) despite the limited number of gauging stations used to obtain the areal rainfall. Furthermore, it was found that Equation (2) is applicable to the upper Chao Phraya River Basin (UCPRB, Figure 1, the basin area is $109,000 \mathrm{~km}^{2}$ ) with the correlation coefficient $r=0.77$ and RMSE $=83.1 \mathrm{~mm}$ for calibration period from 1976 to 2006 (sample number $=17$ ).
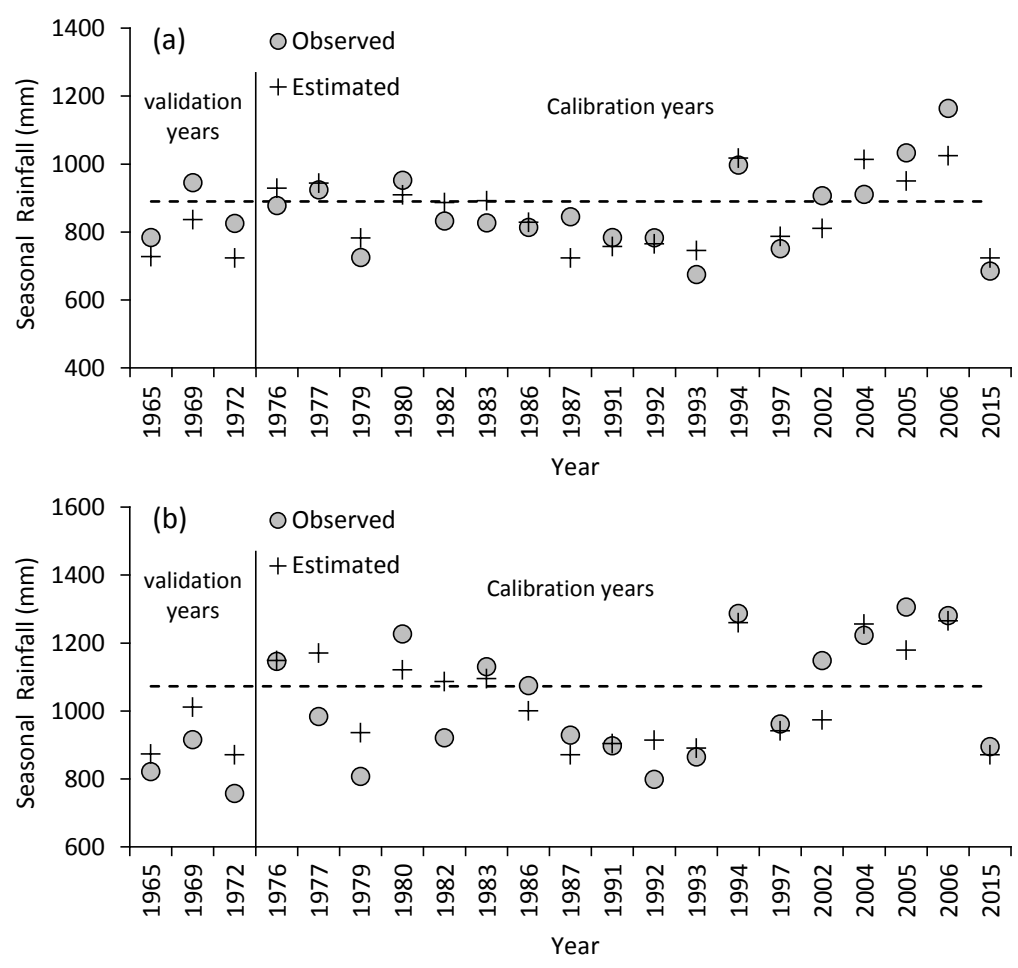

Figure 6. Comparison of observed and estimated seasonal rainfall for (a) PRB and (b) NRB for calibration and validation years with EQ-SOI < 0.02. Equation (2) with calibrated parameters (Table 2) was applied. The dashed line indicates the mean rainfall for the period from 1975 to 2015.

When EQ-SOI is positive, i.e., when the surface trade winds are larger than normal, seasonal rainfall was not significantly related to any one of the tested indices; however, it was positively correlated to EQ-SOI (Figure 9a). Since the arrival and passage of typhoons and tropical cyclones are major causes of increased rainfall, it is likely that the trade winds and SSTs in the Pacific Ocean contribute to these phenomena, with additional influence on seasonal rainfall from the Indian Ocean and monsoon [26]. In this study, we applied an equation that considers interactive and non-linear relationships between the seasonal rainfall and ENSO and SST-related indices for the Pacific Ocean using quadratic functions (Equation (3)). In addition, we tested the inclusion of IMI and DMI as additional components in Equation (6) to consider the influence of the Indian Ocean and monsoon, respectively; however, there was no significant improvement for rainfall estimation:

$$
\begin{gathered}
\mathrm{TR}=\left(g_{1} \times \mathrm{PDO}^{2}+g_{2} \times \mathrm{PDO}+g_{3}\right) \times \mathrm{EQ}-\mathrm{SOI}+d_{0} \\
g_{1}=d_{1} \times \mathrm{SST}^{2}+d_{2} \times \mathrm{SST}+d_{3} \\
g_{2}=d_{4} \times \mathrm{SST}^{2}+d_{5} \times \mathrm{SST}+d_{6}
\end{gathered}
$$




$$
g_{3}=d_{7} \times \mathrm{SST}^{2}+d_{8} \times \mathrm{SST}+d_{9}
$$

where SST is any one of the four SST anomalies over the domain of NINO.WEST, NINO.3, NINO.4, and NINO.34, and $d_{0}-d_{9}$ are the coefficients of the multiple regression analysis. Equation (3) was evaluated with each SST index by the RMSE, multiple correlation coefficient, the similarity of coefficients $d_{1}-d_{9}$ between PRB and NRB, and the consistency with the perceived physical influences, which will be discussed in the following sections.

On average, comparatively high correlation coefficients and small RMSE were obtained for PRB and NRB by applying Equation (3) with the SST anomaly over NINO.WEST (SST ${ }_{N W}$ ). Figure 7 compares the observed and estimated seasonal rainfall during the parameter setting period by the multiple regression analysis. A favorable agreement is found throughout the period, including flood years (1995 and 2011) and drought years (2003), although there are gaps in some years. Thus, we determined that Equation (3) with $\mathrm{SST}_{\mathrm{NW}}$ is suitable within the range of the given climate indices examined, despite the limited flexibility caused by the form (quadratic function).
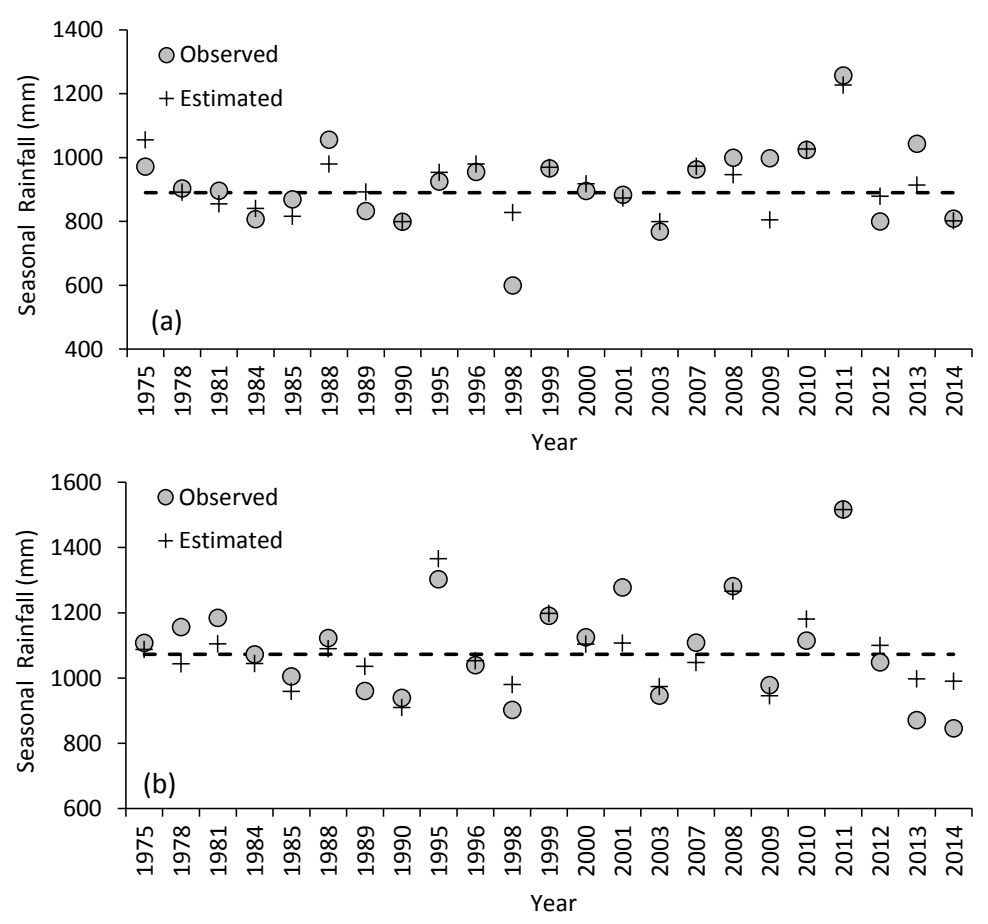

Figure 7. Comparison of observed and estimated seasonal rainfall for (a) PRB and (b) NRB for years with EQ-SOI > 0.02. Equation (3) with NINO.WEST was applied. The dashed line indicates the mean rainfall for the period from 1975 to 2015.

We validated this method by comparing the observed seasonal rainfall during 1966-1974 (when EQ-SOI is positive) with those estimated using Equation (3), resulting in RMSE of 91.0 and $101.4 \mathrm{~mm}$ for PRB and NRB, respectively (Figure 8). These RMSEs are larger than those for the calibration period (during 1975-2014) probably due to the limited number of gauging stations used for APHRODITE products during the period. In addition, we applied multiple regression analysis using Equation (3) to UCPRB (Figure 1), which resulted in satisfactory agreement for both the period of regression analysis between 1975 and 2007 (sample number $=16, r=0.86$, RMSE $=44.6 \mathrm{~mm}$ ) and the period of validation between 1966 and 1974 (sample number $=6, r=0.92$, RMSE $=40.2 \mathrm{~mm}$ ). Table 3 summarizes the results of the proposed Equations (2) and (3) applied to all years between 1975 and 2015. The correlation coefficients were greatly improved from those in previous studies (such as [11]), although the domain and duration differed. 

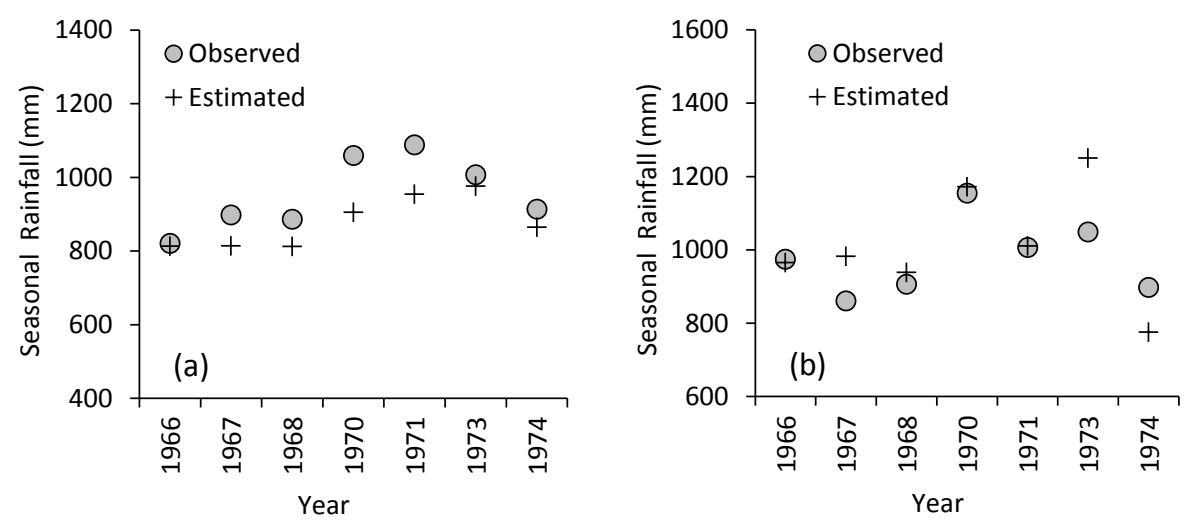

Figure 8. Same as Figure 7 but for validation years between 1966 and 1974 for (a) PRB and (b) NRB.

Table 3. Correlation coefficient $r$ and RMSE for the period from 1975 to 2015 for years of negative EQ-SOI, positive EQ-SOI and all years.

\begin{tabular}{ccccc}
\hline Basin & & EQ-SOI $<\mathbf{0 . 0}$ & EQ-SOI $>\mathbf{0 . 0}$ & All Years \\
\hline \multirow{2}{*}{ PRB } & $r$ & 0.83 & 0.79 & 0.81 \\
& RMSE $(\mathrm{mm})$ & 69.0 & 78.4 & 74.4 \\
\hline \multirow{2}{*}{ NRB } & $r$ & 0.82 & 0.89 & 0.86 \\
& RMSE $(\mathrm{mm})$ & 95.4 & 72.1 & 83.1 \\
\hline
\end{tabular}

\section{Discussion}

The seasonal rainfall data and three climate indices (EQ-SOI, PDO, and $\mathrm{SST}_{\mathrm{NW}}$ ) used in Equation (3) are plotted in Figure 9 to visualize the influence of these indices during years with positive EQ-SOI. Figure 9a shows that EQ-SOI is positively correlated with seasonal rainfall for both PRB and NRB at a significance level less than $5 \%$, while there is no clear difference depending on the PDO phase (Figure 9a). Therefore, it is reasonable to include EQ-SOI as a multiplier of the quadratic function in Equation (3).

In PRB and NRB, the seasonal rainfall during the cool PDO phase $(\mathrm{PDO}<0)$ is $220 \mathrm{~mm}$ and $150 \mathrm{~mm}$ larger than that in the warm phase (PDO >0), respectively, under negative $\mathrm{SST}_{\mathrm{NW}}$ conditions (Figure 9b). However, for years with a positive $\mathrm{SST}_{\mathrm{NW}}$, the differences in seasonal rainfall between the negative and positive PDO phases are much smaller for both basins (below $35 \mathrm{~mm}$ ). There was a negative correlation between PDO and seasonal rainfall in PRB for all plots $(r=-0.42, p=0.02)$, while there was no clear correlation for $\operatorname{NRB}(r=-0.26, p=0.16)$, and seasonal rainfall increases with positive-phase PDO when EQ-SOI exceeds 0.03 (Figure 9b, right). Similar characteristics were observed by Sen Roy and Sen Roy [27], who concluded that monsoon precipitation in eastern Myanmar is positively related to PDO during its warm phase, and negatively correlated during the cold phase. This is considered in the quadratic function.

Seasonal rainfall in both the PRB and NRB is positively correlated with $\mathrm{SST}_{\mathrm{NW}}$, with a $p$-value below $5 \%$, when PDO is positive (Figure 9c), while seasonal rainfall negatively related to $\mathrm{SST}_{\mathrm{NW}}$ when $\mathrm{PDO}$ is negative. A previous study found that the positive (negative) phase of PDO is associated with deficit (excess) rainfall over India [28]. The same phase characteristics were found between annual rainfall in Thailand and an ENSO-related index (MEI) and PDO [29]. Our results indicate that seasonal rainfall cannot be solely related to a single index, and multiple indices (including EQ-SOI) need to be considered when quantifying rainfall. 

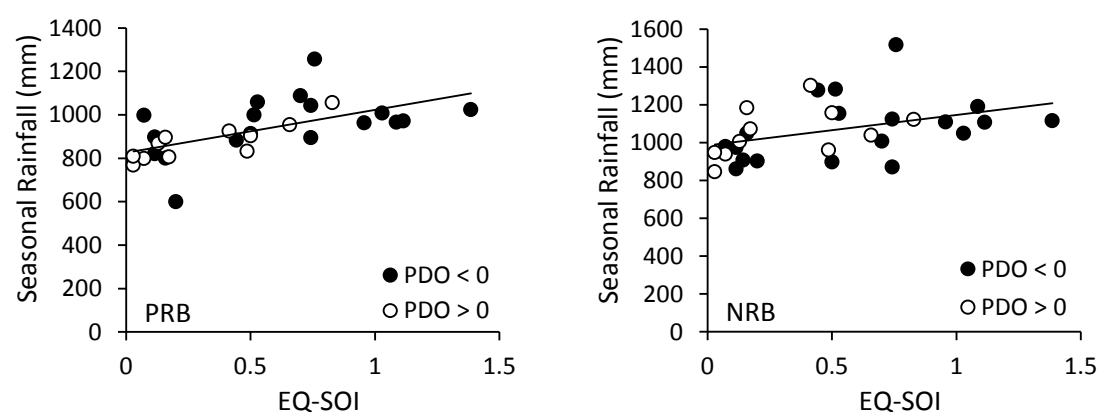

(a)
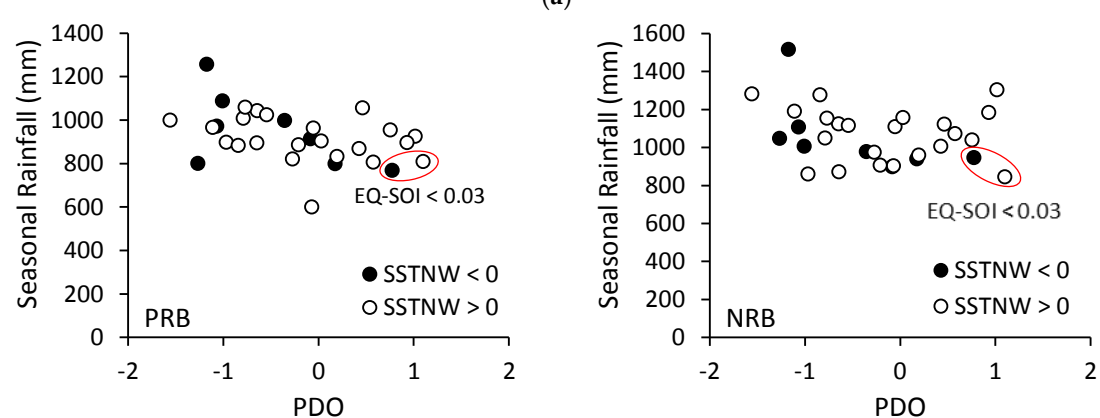

(b)
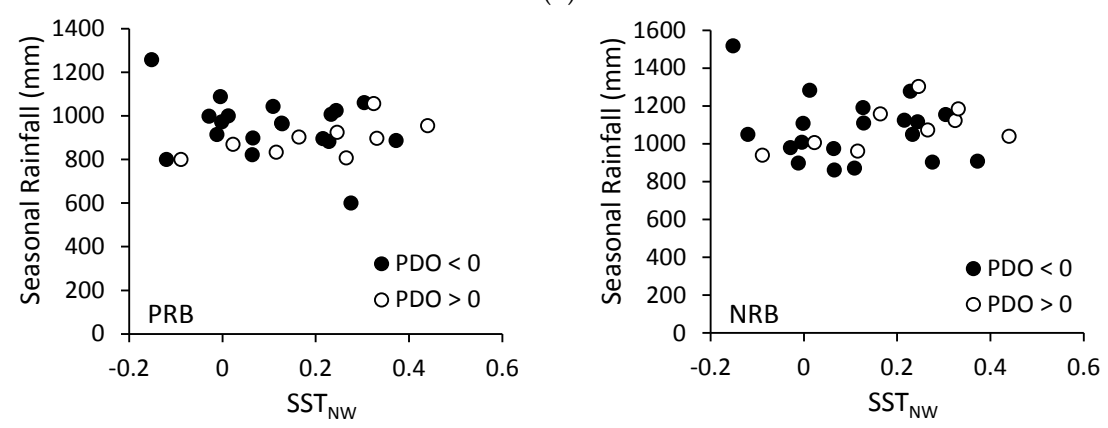

(c)

Figure 9. Relationship between seasonal rainfall and (a) EQ-SOI; (b) PDO and (c) SST $\mathrm{NW}$ for (left) PRB and (right) NRB between 1965 and 2015 (when EQ-SOI is positive).

To highlight the influences of $\mathrm{PDO}$ and $\mathrm{SST}_{\mathrm{NW}}$, we define the normalized rainfall anomaly (Equation (7)) by rearranging Equation (3):

$$
\frac{\mathrm{TR}-d_{0}}{\mathrm{EQ}-\mathrm{SOI}}=g_{1} \times \mathrm{PDO}^{2}+g_{2} \times \mathrm{PDO}+g_{3}
$$

where $g_{1}, g_{2}$, and $g_{3}$ are given by Equations (4)-(6) with calibrated parameters. Figure 10 shows the relationships between the normalized rainfall anomaly and PDO and $\mathrm{SST}_{\mathrm{NW}}$. Each curve in Figure 10 was drawn using Equation (3), and the data plots were limited for years between 1975 and 2015 with EQ-SOI larger than 0.2 for clear indication. Most of the data plots in each class of SST $_{\mathrm{NW}}$ (Figure 10a) or PDO (Figure 10b) are consistent with the corresponding curves with similar $\mathrm{SST}_{\mathrm{NW}}$ or PDO value, respectively, although there are some outliers.

The lines in Figure 10a indicate that PDO increases the normalized rainfall anomaly when it is largely negative or positive for the same or similar $\mathrm{SST}_{\mathrm{NW}}$. Therefore, we confirmed that the sensitivity of Equation (3) is consistent with the recognized influence of PDO, i.e., abundant precipitation tends to occur during La Niña years and the PDO cool phase [29]. Furthermore, the results in Figure 10a suggest that the seasonal rainfall in PRB and NRB can increase with both negative and positive PDO as 
there was no clear relationship between EQ-SOI and PDO when EQ-SOI is positive, which is consistent with the data plots in Figure 9b (especially for NRB) as well as previous analysis [27].

Unlike PDO, the influence of $\mathrm{SST}_{\mathrm{NW}}$ on the normalized rainfall anomaly appears to be more complicated (Figure 10b). For NRB (Figure 10b right), $\mathrm{SST}_{\mathrm{NW}}$ positively affects the normalized rainfall anomaly when $\mathrm{PDO}$ is positive and $\mathrm{SST}_{\mathrm{NW}}$ is within a certain positive range, while the normalized rainfall anomaly is likely to decrease as $\mathrm{SST}_{\mathrm{NW}}$ becomes larger (Figure 10b). These characteristics may be applied to seasonal rainfall itself as there is no certain correlation between EQ-SOI and $\mathrm{SST}_{\mathrm{NW}}$ when EQ-SOI is positive. When PDO is negative, local minima are found for the normalized rainfall anomaly, as indicated by the circle plots and corresponding curve (PDO $=-1.0)$ for NRB in Figure 10b. Similar characteristics were found for PRB, although the variation in the normalized rainfall anomaly is smaller than that for NRB as there was less seasonal rainfall with lower variation over NRB. Although the mechanistic reason for these characteristics is unclear, the normalized rainfall anomaly could be amplified when PDO and $\mathrm{SST}_{\mathrm{NW}}$ are in the same phase. Hoell and Funk [30] reported that, for La Niña events (when EQ-SOI tends to be positive), precipitation is enhanced over the western Pacific and extended to the Indian Ocean during a strong western Pacific SST gradient (WPG), which is defined as the standardized difference between area-averaged SST over the central Pacific Ocean and the domain similar to NINO.WEST. This suggests that SST over NINO.WEST, combined with PDO, could affect precipitation over the Indochina Peninsula through the SST gradient in the western Pacific.
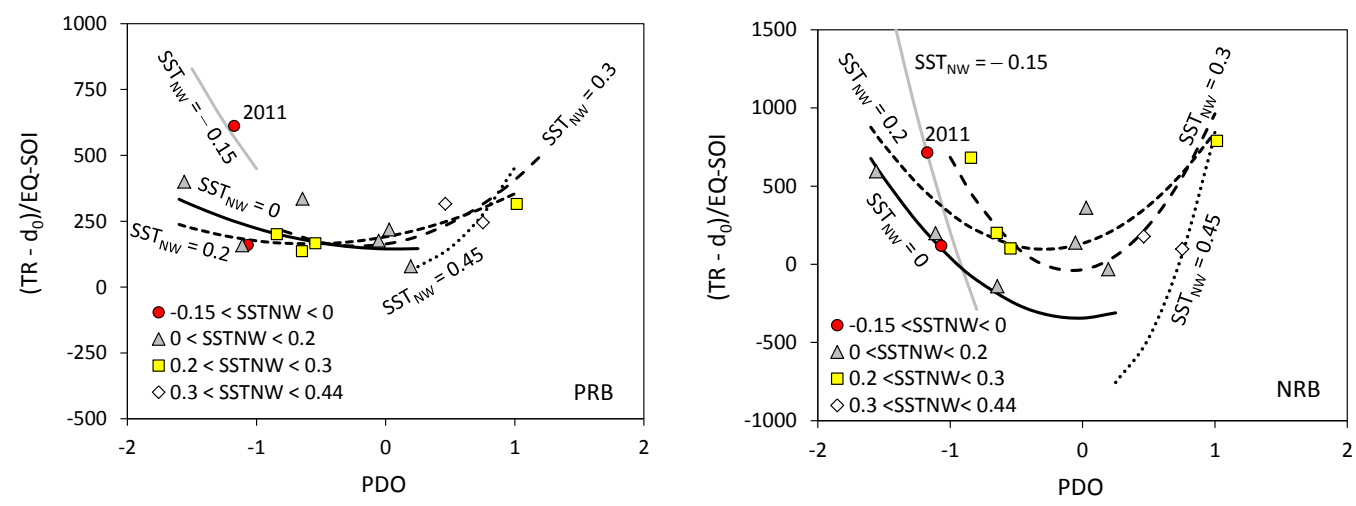

(a)
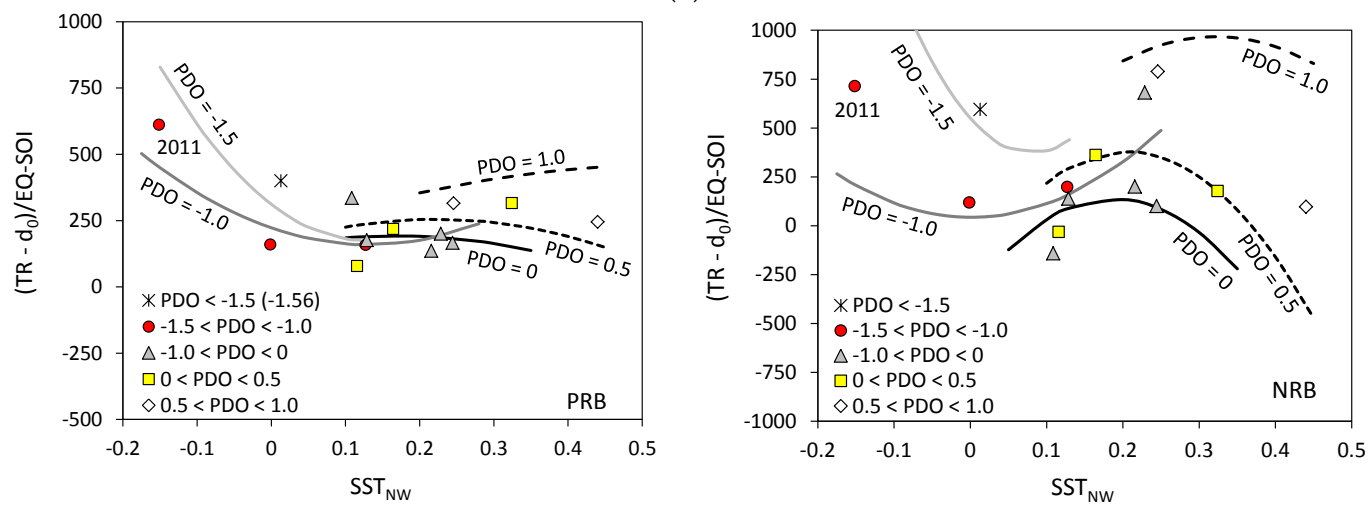

(b)

Figure 10. Relationship between seasonal rainfall and (a) PDO and (b) $\mathrm{SST}_{\mathrm{NW}}$ for (left) PRB and (right) NRB. The vertical axis indicates the seasonal rainfall anomaly divided by EQ-SOI. The solid and dashed curves in each panel are given by Equation (3). Each symbol represents the data when EQ-SOI is positive. 


\section{Conclusions}

The seasonal rainfall over the 50 years during 1965-2015 over the upper Ping River Basin (PRB) and upper Nan River Basin (NRB) in Thailand were analyzed to elucidate a quantitative relationship with existing climate indices. We showed that, when the Equatorial Southern Oscillation index (EQ-SOI) is negative, seasonal rainfall is predominantly related to the Indian Monsoon index (IMI) using a sigmoid function; however, when EQ-SOI is positive, seasonal rainfall is estimated by the

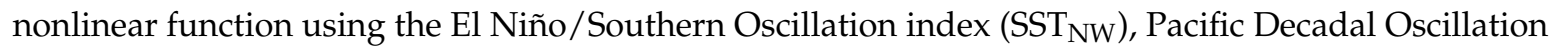
index (PDO), and EQ-SOI. The areal rainfall calculated for the period between 1975 and 2015 from the proposed functions exhibits a high correlation with the observed seasonal rainfall, with correlation coefficients of 0.8 and 0.86 for PRB and NRB, respectively.

Although our proposed method exhibited a relatively high performance for estimating seasonal rainfall, further verification and improvement are necessary by updating the rainfall data and climate indices. Furthermore, to apply the method in practical water resource management, such as dam reservoir operation and the assessment of climate change impacts [31], the use of the forecasted or projected results of selected climate indices should be examined to evaluate the accuracy and uncertainty of seasonal rainfall resulting from the proposed method.

Supplementary Materials: The following are available online at http:/ / www.mdpi.com/2073-4441/10/6/800/s1, Figure S1: Relationship between the areal-mean monthly rainfalls obtained from the APHRODITE dataset (Aphrodite-based) and those calculated by the Thiessen Polygon applied to the rain-gauge data of RID (RID-based) for the period from 1980 to 2000 for (left) PRB and (right) NRB; Figure S2. The number of gauging stations used to calculate the RID-based areal-mean monthly rainfall (red line) and that used to generate the APHRODITE dataset (black line) for (top) PRB and (bottom) NRB.

Author Contributions: Conceptualization, T.K.; Methodology, T.K.; Data collection and processing, A.K., G.Y. and W.L.; Data Analysis, T.K. and G.Y.; Writing-Original Draft Preparation, T.K.; Writing-Review \& Editing, T.K. and W.L.; Visualization, T.K. and G.Y.; Project Administration, T.K. and W.L.

Funding: This work was supported by JSPS Core-to-Core Program, B. Asia-Africa Science Platforms.

Acknowledgments: The authors are grateful to the Royal Irrigation Department for providing useful data for this research.

Conflicts of Interest: The authors declare no conflict of interest.

\section{References}

1. United Nations. Global Assessment Report on Disaster Risk Reduction; United Nations: Geneva, Switzerland, 2009; p. 207. ISBN 9789211320282.

2. Intergovernmental Panel on Climate Change (IPCC). Climate Change 2014: Synthesis Report. Contribution of Working Groups I, II and III to the Fifth Assessment Report of the Intergovernmental Panel on Climate Change; Core Writing Team, Pachauri, R.K., Meyer, L.A., Eds.; IPCC: Geneva, Switzerland, 2014; p. 151. Available online: https://www.ipcc.ch/pdf/assessment-report/ar5/syr/SYR_AR5_FINAL_full_wcover.pdf (accessed on 29 April 2018).

3. Miyan, M.A. Droughts in Asian Least Developed Countries: Vulnerability and sustainability. Weather Clim. Extr. 2015, 7, 8-23. [CrossRef]

4. Tanoue, M.; Hirabayashi, Y.; Ikeuchi, H. Global-scale river flood vulnerability in the last 50 years. Sci. Rep. 2016, 6, 36021. [CrossRef] [PubMed]

5. Dai, A. Increasing drought under global warming in observations and models. Nat. Clim. Chang. 2013, 3, 52-58. [CrossRef]

6. Cai, W.; Borlace, S.; Lengaigne, M.; van Rensch, P.; Collins, M.; Vecchi, G.; Timmermann, A.; Santoso, A.; McPhaden, M.J.; Wu, L.; et al. Increasing frequency of extreme El Niño events due to greenhouse warming. Nat. Clim. Chang. 2014, 4, 111-116. [CrossRef]

7. Cai, W.; Wang, G.; Santoso, A.; McPhaden, M.J.; Wu, L.; Jin, F.-F.; Timmermann, A.; Collins, M.; Vecchi, G.; Lengaigne, M.; et al. Increased frequency of extreme La Niña events under greenhouse warming. Nat. Clim. Chang. 2015, 5, 132-137. [CrossRef] 
8. Komori, D.; Nakamura, S.; Kiguchi, M.; Nishijima, A.; Yamazaki, D.; Suzuki, S.; Kawasaki, A.; Oki, K.; Oki, T. Characteristics of the 2011 Chao Phraya River flood in central Thailand. Hydrol. Res. Lett. 2012, 6, 41-46. [CrossRef]

9. Promchote, P.; Wang, S.S.-Y.; Johnson, P.G. The 2011 Great Flood in Thailand: Climate Diagnostics and Implications from Climate Change. J. Clim. 2016, 29, 367-379. [CrossRef]

10. Ueangsawat, K.; Jintrawet, A. The Impacts of ENSO Phases on the Variation of Rainfall and Stream Flow in the Upper Ping River Basin, Northern Thailand. Environ. Nat. Resour. J. 2013, 11, 97-119.

11. Tsai, C.; Behera, S.K.; Waseda, T. Indo-China Monsoon Indices. Sci. Rep. 2015, 5, 8107. [CrossRef] [PubMed]

12. Singhrattna, N.; Rajagopalan, B.; Clark, M.; Krishna Kumar, K. Seasonal forecasting of Thailand summer monsoon rainfall. Int. J. Climatol. 2005, 25, 649-664. [CrossRef]

13. Divakar, L.; Babel, M.S.; Perret, S.R.; Das Gupta, A. Optimal allocation of bulk water supplies to competing use sectors based on economic criterion-An application to the Chao Phraya River Basin, Thailand. J. Hydrol. 2011, 401, 22-35. [CrossRef]

14. Takeda, M.; Laphimsing, A.; Putthividhya, A. Dry season water allocation in the Chao Phraya River basin, Thailand. Int. J. Water Resour. Dev. 2015, 32, 321-338. [CrossRef]

15. Kripalani, R.H.; Singh, S.V.; Panchawagh, N.; Brikshavana, M. Variability of the summer monsoon rainfall over Thailand-Comparison with features over India. Int. J. Climatol. 1995, 15, 657-672. [CrossRef]

16. Yatagai, A.; Kamiguchi, K.; Arakawa, O.; Hamada, A.; Yasutomi, N.; Kitoh, A. APHRODITE: Constructing a Long-term Daily Gridded Precipitation Dataset for Asia based on a Dense Network of Rain Gauges. Bull. Am. Meteorol. Soc. 2012, 93, 1401-1415. [CrossRef]

17. Matsumoto, J. Seasonal transition of summer rainy season over Indochina and adjacent monsoon region. Adv. Atmos. Sci. 1997, 14, 231-245. [CrossRef]

18. Wang, B.; Fan, Z. Choice of South Asian summer monsoon indices. Bull. Am. Meteorol. Soc. 1999, 80, 629-638. [CrossRef]

19. Mantua, N.J.; Hare, S.R.; Zhang, Y.; Wallace, J.M.; Francis, R.C. A Pacific decadal climate oscillation with impacts on salmon. Bull. Am. Meteorol. Soc. 1997, 78, 1069-1079. [CrossRef]

20. Saji, N.H.; Goswami, B.N.; Vinayachandran, P.N.; Yamagata, T. A dipole mode in the tropical Indian Ocean. Nature 1999, 401, 360-362. [CrossRef] [PubMed]

21. NOAA National Weather Service Climate Prediction Center. Available online: http:/ / www.cpc.ncep.noaa. gov/data/indices/ (accessed on 29 April 2018).

22. University of Hawaii, International Pacific Research Center (IPRC). Available online: http:/ / apdrc.soest. hawaii.edu/projects/monsoon/index.html (accessed on 29 April 2018).

23. Japan Meteorological Agency. Available online: http://ds.data.jma.go.jp/tcc/tcc/products/elnino/index/ (accessed on 29 April 2018).

24. NOAA ESRL Physical Sciences Division. Available online: http://www.esrl.noaa.gov/psd/gcos_wgsp/ Timeseries/PDO/ (accessed on 29 April 2018).

25. JAMSTEC. Available online: http://www.jamstec.go.jp/frsgc/research/d1/iod/iod/dipole_mode_index. html (accessed on 29 April 2018).

26. Meyers, G.; McIntosh, P.; Pigot, L.; Pook, M. The years of El Niño, La Niña, and interactions with the tropical Indian Ocean. J. Clim. 2007, 20, 2872-2880. [CrossRef]

27. Sen Roy, S.; Sen Roy, N. Influence of Pacific decadal oscillation and El Niño Southern oscillation on the summer monsoon precipitation in Myanmar. Int. J. Climatol. 2011, 31, 14-21. [CrossRef]

28. Krishnamurthy, L.; Krishnamurthy, V. Influence of PDO on South Asian summer monsoon and monsoon-ENSO relation. Clim. Dyn. 2014, 42, 2397-2410. [CrossRef]

29. Limsakul, A.; Singhruck, P. Long-term trends and variability of total and extreme precipitation in Thailand. Atmos. Res. 2016, 169, 301-317. [CrossRef]

30. Hoell, A.; Funk, C. The ENSO-Related West Pacific Sea Surface Temperature Gradient. J. Clim. 2013, 26, 9545-9562. [CrossRef]

31. Singhrattna, N.; Babel, M.S. Changes in summer monsoon rainfall in the Upper Chao Phraya River Basin, Thailand. Clim. Res. 2011, 49, 155-168. [CrossRef] 
(C) 2018 by the authors. Licensee MDPI, Basel, Switzerland. This article is an open access article distributed under the terms and conditions of the Creative Commons Attribution (CC BY) license (http:/ / creativecommons.org/licenses/by/4.0/). 